\title{
A COMPARATIVE STUDY OF STUDENT ACADEMIC PERFORMANCE IN ON-CAMPUS TEACHING AND DISTANCE LEARNING IN A COMPUTER ENGINEERING PROGRAMME
}

\author{
C. K. Osei and J. A. Mensah \\ Institute of Distance Learning \\ Kwame Nkrumah University of Science and Technology, Kumasi
}

\begin{abstract}
The purpose of this study was to examine the differences in academic performance of students in distance learning and on-campus programmes in a Computer Engineering programme at the Kwame Nkrumah University of Science and Technology, Ghana. The study employed descriptive and inferential statistics for analysing the data from 76 students, drawn from the Computer Engineering Programme. The findings of the study suggested no significant differences of academic performance (Cumulative Weighted Average Scores) between distance and on-campus students. However there were statistically significant differences between the two groups in 20 of the 43 courses with the on-campus students scoring higher marks than the distance students. We found weak correlation between age, admission aggregates and CWA scores of on-campus and distance learning students in the two separate learning environments. The lack of a statistically significant correlation between the variables suggests that age and admission aggregates are not strong predictors of CWA scores in the two learning modes. It can be concluded that distance learning could be used as a viable alternative educational methodology for the delivery of computer engineering courses.
\end{abstract}

Keywords: Computer engineering, distance learning, on-campus teaching, academic performance

\section{INTRODUCTION}

The Kwame Nkrumah University of Science and Technology (KNUST) has since 2005 offered Distance Learning (DL) programmes in response to the challenge of providing increased opportunities for tertiary education.

The BSc. Computer Engineering programme is one of the several programmes that is offered in both the on-campus face-to-face teaching and distance learning modes in KNUST. The programme covers courses that include Engi- neering Technology, Information Technology, Communication Systems and Applied Electricity.

Entry requirements into the programme and the curriculum for the 2006/7 to 2008/9 cohort of on-campus and distance learning students have been the same. Other similarities of the two groups were same examinations and same grading matrix. However a major difference between the two groups was the delivery mode. 
The students attending the on-campus programme attend lectures during the weekdays while the mode of delivery of the DL programme is predominantly by print medium supplemented by occasional face-to-face tutorials during weekends with the facilitator present.

According to UNESCO (2002), the terms open and distance learning represent approaches that focus on opening access to education and training provision, freeing learners from the constraints of time and place and offering flexible learning opportunities to individuals and groups of learners. Distance Learning practitioners have shown interest in comparing the effectiveness of DL mode with the on-campus face-to-face teaching. The frequently asked question is whether DL is as effective as oncampus face-to-face teaching. For this reason, researchers have often compared academic performance of distance learners to their oncampus counterparts. Russell et al. (2008) reported in a comparative study of DL and oncampus face-to-face students in health informatics that there were no significant differences between the two groups on final Grade Point Average (GPA) scores. Shen et al. (2007), using measurable students' outcomes as an important indicator reported that studying at a distance can be as effective as traditional instruction. Bernard et al. (2004) performed a meta-analysis of 232 comparative studies to determine the effectiveness of DL. This metaanalysis found that some researchers reported that DL worked well for some students while others reported that it worked very poorly.

However, Bernard et al. (2004) found that DL students had slightly higher overall achievement than traditional on-campus students. Different results have been reported on gender and age when comparing academic performance of DL and on-campus students. Cheung and Kan (2002) reported that gender was significantly related to academic achievement while age was not in the DL environment. However Barakzai and Fraser (2005) found no significant differ- ence in academic performance between men and women in the two courses in health care education.

Despite the numerous studies that have compared the effectiveness of distance learning mode with the on-campus teaching, little is known about published studies that compare the academic performance of Distance Learners and on-campus students in dual mode institutions in developing countries like Ghana. This study was aimed at determining if there were any significant differences in academic performance between DL and traditional oncampus students in B.Sc. Computer Engineering. Another aim was to determine how academic performance is affected by age, and admission aggregates between the groups of students in the two separate learning environments. Both groups were therefore studied to determine whether there were any relationships between age, overall admission aggregates, single course scores and Cumulative Weighted Average (CWA) scores.

Thus it was hypothesised that:

1. There are no significant differences in the academic performance (CWA and Course scores) of DL and on-campus Computer Engineering students.

2. There are no relationships between age, admission aggregates and academic performance (i.e. CWA scores) of DL and on -campus Computer Engineering students in the two separate learning environments.

\section{METHODOLOGY}

The sampling frame consisted of 76 students made up of 50 on-campus students and 26 distance learning students. This cohort of students (2006/7 academic year) was chosen for the study because the students in both environments have had exactly the same content and took the same examination. Given the relatively small population size, we did not draw a sample from the sampling frame. The sampling frame therefore matches the population. 
A causal-comparative research design was used and academic performance was measured by CWA scores and single course scores of distance and on-campus learners. Academic performance was the dependent variable in the study and the independent variable was the learning style (either distance or on-campus). Permission was granted to researchers to use data on student's age, gender, admission aggregate, single course scores and CWA scores from the databases of the Department of Computer Engineering, the Planning Office and the IDL of the KNUST.

Descriptive statistics were performed to show means and percentages of on-campus and distance learning students on their characteristics. Independent two-sample $t$-tests were performed to determine if there were any statistically sig- nificant differences between the distance and on-campus learners for overall CWA, and individual course scores. Correlation analyses were employed to establish the validity of the hypothesis that the age, and admission aggregates are not related to the CWA scores of students.

\section{RESULTS AND DISCUSSION}

A total of 76 sets of students' data were collected for the study; 50 of these were from the on-campus students and 26 from distance learning students. A base demographic analysis of the two groups was conducted (Table 1). With regard to gender, males constituted the majority for both the on-campus (92\%) and distance $(100 \%)$ students indicating total male dominance of the programme in both teaching modes. Researchers like Przymus (2004) and Plummer (2002) have indicated in their studies

Table 1: Variable labels and descriptive statistics

\begin{tabular}{|c|c|c|c|c|}
\hline \multirow[b]{2}{*}{ Variable Labels } & \multicolumn{2}{|c|}{ On-Campus Students } & \multicolumn{2}{|c|}{ Distance Learning Students } \\
\hline & $\begin{array}{l}\text { Frequency } \\
(\mathbf{N}=\mathbf{5 0})\end{array}$ & $\begin{array}{l}\% \text { of Respon- } \\
\text { dents }\end{array}$ & $\begin{array}{l}\text { Frequency } \\
(\mathbf{N}=\mathbf{2 6})\end{array}$ & $\begin{array}{l}\% \text { of Respon- } \\
\text { dents }\end{array}$ \\
\hline \multicolumn{5}{|l|}{ Gender } \\
\hline Male & 45 & 90 & 26 & 100 \\
\hline Female & 5 & 10 & 0 & 0 \\
\hline \multicolumn{5}{|l|}{ Age (years) } \\
\hline $20-30$ & 49 & 98 & 9 & 34 \\
\hline $31-40$ & 1 & 2 & 12 & 46.2 \\
\hline $40-50$ & 0 & 0 & 4 & 15.4 \\
\hline$>50$ & 0 & 0 & 1 & 3.8 \\
\hline Mean age & 23 & & 36 & \\
\hline \multicolumn{5}{|l|}{$\begin{array}{l}\text { Admission } \\
\text { aggregate }\end{array}$} \\
\hline$<10$ & 39 & 78 & 1 & 3.8 \\
\hline $10-14$ & 6 & 12 & 2 & 7.7 \\
\hline $15-19$ & 5 & 10 & 19 & 74.1 \\
\hline $20-24$ & 0 & 0 & 4 & 15.4 \\
\hline Mean aggregate & 10 & & 17 & \\
\hline \multicolumn{5}{|l|}{ CWA scores } \\
\hline $40-49$ & 9 & 18 & 4 & 15.4 \\
\hline $50-59$ & 15 & 30 & 12 & 46.2 \\
\hline $60-69$ & 23 & 46 & 10 & 38.5 \\
\hline 70-79 & 3 & 6 & 0 & 0 \\
\hline Mean CWA & 58.92 & & 57.69 & \\
\hline
\end{tabular}


100 Osei and Mensah

Table 2: $T$-test values for academic performance (CWA and course scores)

\begin{tabular}{lcccccccccc}
\hline & \multicolumn{2}{c}{ On-Campus } & & \multicolumn{3}{c}{ Distance } & & & $\boldsymbol{t}$-value & $\begin{array}{l}\text { Sig. 2- } \\
\text { tailed* }\end{array}$ \\
Variables & Min & Max & Mean & $\mathbf{S}_{\mathbf{d}}$ & Min & Max & Mean & $\mathbf{S}_{\mathbf{d}}$ & & \\
\hline CWA & 41.9 & 73.4 & 58.92 & 7.73 & 46.02 & 67.32 & 57.69 & 5.55 & 0.714 & 0.477 \\
Year 1 Courses & & & & & & & & & \\
ME 161 & 32 & 100 & 78.22 & 14.1 & 27 & 85 & 60.62 & 13.5 & 5.259 & .000 \\
ME 159 & 26 & 87 & 64.72 & 12.3 & 33 & 84 & 56.58 & 10.5 & 2.870 & .005 \\
ENGL 157 & 43 & 83 & 68.04 & 7.5 & 41 & 81 & 63.23 & 10.2 & 2.341 & .022 \\
CE 155 & 67 & 97 & 85.66 & 6.49 & 59 & 89 & 78.36 & 6.95 & 4.527 & .000 \\
MATH 152 & 24 & 76 & 45.08 & 10.7 & 40 & 76 & 58.81 & 10.4 & -5.350 & .000 \\
Year 2 Courses & & & & & & & & & \\
EE 291 & 60 & 83 & 75.90 & 4.43 & 51 & 78 & 68.08 & 7.84 & 5.571 & .000 \\
ENGL 263 & 55 & 88 & 67.66 & 6.4 & 40 & 70 & 58.00 & 6.66 & 6.156 & .000 \\
COE 251 & 18 & 89 & 57.12 & 18.8 & 40 & 62 & 49.12 & 7.09 & 2.085 & .040 \\
COE 292 & 46 & 97 & 90.32 & 7.02 & 60 & 80 & 72.31 & 5.17 & 11.546 & .000 \\
EE 288 & 26 & 93 & 58.50 & 14.3 & 28 & 70 & 49.92 & 10.2 & 2.680 & .009 \\
ENGL 264 & 52 & 79 & 69.12 & 6.29 & 40 & 77 & 62.85 & 8.27 & 3.692 & .000 \\
TE 262 & 31 & 75 & 58.86 & 10.2 & 45 & 90 & 67.96 & 13.7 & -3.282 & .002 \\
COE 252 & 16 & 81 & 57.74 & 14.8 & 24 & 73 & 49.58 & 11.7 & 2.441 & .017 \\
Year 3 Courses & & & & & & & & & \\
EE 387 & 32 & 85 & 59.90 & 12.9 & 40 & 75 & 54.15 & 9.18 & 2.023 & .047 \\
COE 381 & 40 & 77 & 58.30 & 11.2 & 33 & 76 & 52.77 & 12.1 & 1.988 & .050 \\
TE 361 & 32 & 84 & 58.38 & 13.8 & 41 & 77 & 45.31 & 10.3 & 4.206 & .000 \\
EE 371 & 40 & 86 & 65.62 & 14.2 & 26 & 67 & 58.46 & 9.69 & 2.321 & .023 \\
MATH 351 & 30 & 82 & 58.58 & 9.34 & 60 & 85 & 71.88 & 7.92 & -6.196 & .000 \\
COE 368 & 26 & 68 & 48.24 & 8.87 & 31 & 64 & 44.23 & 6.92 & 2.007 & .048 \\
COE 354 & 36 & 74 & 54.28 & 9.08 & 40 & 76 & 62.50 & 7.71 & -3.935 & .000 \\
\hline
\end{tabular}

*Significant difference at 0.05 level $(p<0.05)$

that women in DL are under-represented in science, technology, technical and mathematics oriented courses.

Descriptive statistics showed that distance students comprised the majority of the older students. According to Dubios (2003), DL encourages older people to seek higher education. Also the results indicated that majority of the on-campus students were admitted with better aggregate scores.

The results of the $t$-test for academic performance (CWA and course scores) are listed in
Table 2. CWA scores and course scores were used as a measure of academic performance. The mean CWA score for on-campus students was 58.92 and 57.69 for the distance learners. The mean course scores for the two groups that were found statistically significant are shown in Table 2. There was no significant difference in the mean CWA scores between distance and on -campus students. However, there were statistically significant differences between the two groups in 20 of the 43 course scores with the on -campus students scoring higher than the distance students in 20 courses (Table 2). These differences though numerically of statistical 
Performance in On-Campus Teaching and Distance Learning... 101

significance, do not stretch to CWA scores. On the basis of the $t$-test, the evidence supports the hypothesis that there are no significant differences in the academic performance (CWA scores) of distance learning and on-campus Computer Engineering students.

To determine if there were any relationships between age, admission aggregates and CWA scores, correlation analyses were performed for the on-campus and distance learning students separately. Table 3 shows the results of the Pearson correlation analyses.

For the on-campus students the correlation coefficient for age and admission aggregate scores was -0.1139; age and CWA scores was 0.0281 ; For the distance learning students the values were 0.2642 and -0.1396 respectively. The on-campus students had a correlation coefficient of -0.1595 for admission aggregate scores and CWA scores. The distance learning students' correlation coefficient for admission aggregate scores and CWA scores was -0.1902 .

The results indicate weak correlation between the variables within the two separate learning environments. For the on-campus students, the correlation coefficient ranged from -0.1139 to 0.0281 while that of distance students had values ranging from -0.1396 to 0.2642 . even though the results show relationships between student age, admission aggregates and CWA scores, the results are not statistically significant. On the basis of the correlation analysis, the hypothesis that age and admission aggregates are not related to the CWA scores of students is rejected.

\section{CONCLUSION}

This study has shown that distance learning students perform well academically as their oncampus counterparts when comparing CWA and Course scores. Therefore, it can be concluded that studying at a distance can be as effective as on-campus teaching of computer engineering courses. The study however revealed weak relationships between student age, admission aggregates and CWA scores in the two separate learning environments. The lack of statistically significant correlation between student age and CWA scores and between admission aggregates and CWA scores suggest that age and admission aggregates are not strong predictors of CWA scores in the two learning modes.

Further research will need to be conducted with larger sample sizes in addition to research studies that examine other relationships in the programme. This will reassure educators, potential students (or beneficiaries), policy makers and employers that distance learning is a viable alternative to the traditional on-campus face-to-

Table 3: Correlation statistics for the on-campus and distant learning students

\begin{tabular}{lllllll}
\hline & \multicolumn{2}{c}{ On-Campus Students } & \multicolumn{3}{c}{ Distance Students } \\
& Age & $\begin{array}{c}\text { Admission } \\
\text { Aggregate }\end{array}$ & $\begin{array}{l}\text { CWA } \\
\text { Scores }\end{array}$ & Age & $\begin{array}{l}\text { Admission } \\
\text { Aggregate }\end{array}$ & $\begin{array}{l}\text { CWA } \\
\text { Scores }\end{array}$ \\
\hline Age & - & -0.1139 & 0.0281 & - & 0.2642 & -0.1396 \\
$\begin{array}{l}\text { Admission } \\
\text { aggregate }\end{array}$ & & - & -0.1595 & & - & -0.1902 \\
CWA scores & & & - & & & - \\
Mean & 22.62 & 9.86 & 58.91 & 34.62 & 17.38 & 57.69 \\
Number & 50 & 50 & 50 & 26 & 26 & 26 \\
\hline
\end{tabular}

*Significant difference at 0.05 level $(p<0.05)$ 
face instruction as far as academic performance is concerned.

\section{REFERENCES}

Barakzai, M. D., and Fraser D. (2005). the Effect of Demographic Variables on Achievement in and Satisfaction with Online Coursework. Journal of Nursing Education 44(8): 373-380

Bernard, R. M., Abrami P. C. , Lou Y., Borokhovski, E., Wade, A., Wozney, L., Wallet P. A., Fiset, M. and Huang, B. (2004). "How Does Distance Education Compare with Classroom Instruction? A Metaanalysis of the Empirical Literature." Review of Educational Research 74 (3): 379 -439 .

Cheung, L. L. W. and Kan, A. (2002). Evaluation of Factors Related to Student Performance in Distance-Learning Business Communication Course. Journal of Education for Business 77 (5):257-263.

Dubios, J. (2003). Major issues in distance learning. Working Connections. IT Faculty Development Institute. [Presentation].

Plummer, V. C. (2000). Women and Distance Education. London: Routledge.

Przymus (2004). A simple way to increase per- sistence in distance education. Women in Higher Education 13(1):35-46

Russell, B. L., Barefield, A. C., Turnbull, D., Leibach, E. and Pretlow, L. (2008). Evaluating Distance Learning in Health Informatics Education Perspect Health Information Management Association 5:5 Published on-line. Assessed October 25, 2010 from http://perspectives.ahima.org / index.php? option= com_content\&view=article \&id=113: evaluating-distance-learning-in-healthinformatics -education \& catid=38: educa $\underline{\text { tion-a-careers } \& \text { Itemid }=84}$

Qiping, S., Chung, J. K. H., Challis D., a n d Cheung, R. C. T. (2007), A comparative study of student performance in traditional mode and online mode of learning. Accessed October 25, 2010 from http:// www.quo.edu/arabic/researchProgram/ \begin{tabular}{llllllll} 
eLearningResearchs/ & o & $m$ & $p$ & a & r & a \\
\hline
\end{tabular} tiveStudy.pdf

UNESCO (2002) Open and Distance Learning Trends, Policy and Strategy Considerations. Division of Higher Education. Accessed October 2, 2010 from http:/ unesdoc.unesco.org / i m a g e s / 00012 / $\underline{001284 / 1284 \text { e.pdf }}$ 